\title{
1. Introduction to Entrepreneurial Ecosystems Meet Innovation Systems: Synergies, policy lessons and overlooked dimensions
}

\author{
Jana Schmutzler, Rhiannon Pugh and \\ Alexandra Tsvetkova
}

Systemic approaches to economic development have burgeoned recently in the wake of the emergence of a distinct research subfield that studies entrepreneurial ecosystems (EE) (for example, Mason \& Brown, 2014 and Malecki, 2018). Drawing on the biological metaphor of "a biotic community, its physical environment, and all the interactions possible in the complex of living and nonliving components" (Moore, 1963, p. 249), the concept of EE is shaping understanding of entrepreneurship as an evolutionary, socially interactive and non-linear process (Colombelli, Paolucci \& Ughetto, 2017).

This research area complements a long-standing interest in other "flavors" of systemic conceptualizations of the interlinked - and embedded in local context - spheres of innovation, institutions and economic development that have been popular in academic and policy practice communities (Uriona-Maldonado, dos Santos \& Varvakis, 2012; Teixeira, 2014; Malecki, 2018). The idea that a place's community, and its economic and social contexts matter, however, is at least a century old. A focus on a multitude of actors, the environment and their dynamic network-like interactions in explanations of regional economic performance has given rise to concepts such as industrial districts (Marshall, 1920 [1890]), industrial clusters (Porter, 2000), innovative milieu (Camagni, 1991) and, lately, the (national/regional/technological) innovation systems (IS) (Lundvall, 1992; Asheim, Smith \& Oughton, 2011; Carlsson \& Stankiewitz, 1991).

Overall, these systemic frameworks prove enduringly popular, perhaps due to their ability to capture and explicate mechanisms usually assumed away in static analyses within classical economics. The rapid improvements in data, estimation techniques and computational power make it easier to account for and to track the complexity of the local and global interactions within systems. 
This is likely to further expand and deepen research interest in (and policy applications of) the systems-inspired perspectives on economic processes.

This book presents current multidisciplinary research of diverse authors, which expands our knowledge about three dimensions of the systemic frameworks. The first part explores the promise but also the limits of bridging the EE and the IS concepts, particularly as applied outside of the bubbling global hubs or to the types of entrepreneurship different from the high-growth variety. Building on these insights, the second part of the book delves deeper into the links between academic knowledge and its practical applications in a variety of contexts - from a vibrant London suburb to Latin American countries - with the goal of offering place-specific policy implications. Finally, the last part of the book presents some of the overlooked dimensions of the systems perspectives, which are important for expanding the scope of the inquiry but also for a better understanding of the strengths and weaknesses of the current debates.

\subsection{THE INNOVATION SYSTEM AND ENTREPRENEURIAL ECOSYSTEM: AN OVERVIEW}

The systems approaches have been around for a while. Starting with the early works by Lundvall and Nelson (Lundvall 1988, 1992; Nelson, 1993), researchers used the systems logic to understand economic activity and growth at a variety of levels (e.g. localities, regions, sectors, etc.). The policy relevance of the systems approach is clear to see over time. McCann and Ortega-Argilés (2013) credit the IS thinking with shifting the predominant policy approaches to economic development away from a narrow science policy towards much broader systemic views on national and regional innovation. Systems thinking has permeated policy at regional, national and supranational levels: Lundvall (2007a) and Edquist (2005) highlight systems-premised policy advice developed by various actors such as the Organisation for Economic Co-operation and Development (OECD) (the Directorate of Science, Technology and Industry, currently the Directorate for Science, Technology and Innovation), the United Nations Conference on Trade and Development and its Industrial Development Organization and VINNOVA (the Swedish Agency for Innovation). More recently, ecosystemic perspectives are being developed at the World Bank (2010) and the Local Economic and Employment Development (LEED) Programme at the OECD Centre for Entrepreneurship, SMEs, Regions and Cities (Mason \& Brown, 2014).

The IS perspective has evolved over the last three decades of work on innovation dynamics and policy from local, regional and national perspectives; it is now well established as a lens through which we can examine innovation processes and also as an influential framework for the design and delivery of 
innovation policy (Edquist, 2005; Lundvall, 2007a). Definitions of IS abound: summarizing these, Asheim finds that within the literature, the IS can be defined broadly, including the "wider organisations and institutions affecting and supporting learning and innovation", or narrowly, examining the "R\&D [research and development] functions of universities, public and private research institutes and corporations" (2012, p. 995). According to Lundvall (2007a), it is the wide understanding that is most useful and appropriate, but policy often conceptualizes IS narrowly. From its origins in work on national IS (Lundvall, 1988, 1992; Nelson, 1993), IS approaches have since evolved into regional (Cooke, 1998; Malmberg \& Maskell, 1997), technological (Carlsson \& Stankiewitz, 1991) and sectoral systems of innovation (Breschi \& Malerba, 1997).

The IS framework has challenged the mainstream economics view and the prevailing policy approaches (cf. Lundvall, 2007a). We can credit the IS work with shifting our understanding of innovation and economic development towards more evolutionary and interactive ways of thinking and seeing (Pugh, 2014). The IS approach is notable for its focus on learning, knowledge, networks and institutions as the central elements in enabling but also hindering innovation in different contexts (Cooke, 1998; Doloreux, 2002; Edquist, 2005; Lundvall, 1992). Most importantly, within the IS perspective, innovation is geographically, socially and historically contingent (Doloreux and Parto, 2005; Freeman, 2002; Lundvall, Johnson, Andersen \& Dalum, 2002).

Because of a relatively long application of the IS concept both empirically and theoretically, we already have a critical body of work to draw on to better understand the strengths and weaknesses of the concept. A thorough review of these is provided by Edquist (2005). He identifies the strengths of the IS approach as: the holistic and interdisciplinary view; the historical and evolutionary perspectives it encompasses; the interdependence and non-linearity of the approach; and the central role of institutions in explaining the innovation process (Edquist, 2005, p. 185). On the other hand, the concept suffers from fuzziness. For example, it lacks a definition for an institution and specifications for what should be included or excluded from the system and where the system boundaries are (Edquist, 2005). Doloreux and Parto (2005) agree with this perspective, finding some definitional and conceptual stickiness around the regional variant of the IS concept. The inherent problem of a fuzzy theoretical approach is not universally derided: whilst some theorists think the IS approaches need to be rendered more "theory-like" and to strengthen their foundations in the neo-Schumpeterian and evolutionary economic thinking (e.g. Fischer, 2001; Lundvall, 2002, 2003; Lundvall et al., 2002), others see conceptual openness and flexibility as a key strength of the IS approach (Nelson and Rosenberg, 1993), allowing it to be applied in a variety of contexts (Edquist, 2005). 
Recently, a newer concept within the field of entrepreneurship, innovation and economic development - entrepreneurship (or entrepreneurial) ecosystems - experienced a ballooning of interest amongst the academic as well as policy practice and advice communities. The World Bank (2018), the OECD (Mason \& Brown, 2014; OECD, 2014, 2019) as well as national-level policy actors such as the German development agency GIZ (Kreuzer et al., 2018) and Scotland Can Do sponsored by the Scottish Government (2018) employ this concept in their work.

Academically, the concept of EE has gained popularity since the publication of Isenberg's (2010) piece in the Harvard Business Review and the mainstream book "Startup Communities" (Feld, 2012). Both authors highlight the importance of a supportive community as well as an enabling economic environment for the entrepreneur. As such, these publications embody a changing research focus in the entrepreneurship literature: away from personality-based explanations toward investigations of the entrepreneurial process in its broader social and economic environment (Spigel, 2017). The EE concept has proven particularly popular amongst scholars in entrepreneurship, management and economic geography also due to its focus on the local and regional context.

\subsection{BRIDGING INNOVATION SYSTEMS WITH ENTREPRENEURIAL ECOSYSTEMS: WHAT CAN BE LEARNED?}

As of today, the IS and EE perspectives have established themselves in their own right. Despite Schumpeter's (2003 [1911]) conceptualization (in his early work) of the "entrepreneur as innovator" who drives economic development, it appears that the IS and EE literatures mainly evolve along parallel lines with limited dialogue (Acs, Autio \& Szerb, 2014). This is surprising given that the IS approach is often considered a predecessor of the EE framework (Stam \& Spigel, 2017) and that the two perspectives often share the same methodological tools and address very closely related, if not similar, issues.

The IS and the EE concepts are rooted in the theoretical (eco)systemic foundation. This allows them to depart from the (near) linear view of economic growth by the neoclassical economic theory to try and comprehend the economic trajectory of a place from a broader perspective, which includes a multitude of actors and factors working at many levels.

Ironically, the two concepts are very similar in their received critiques. Castellacci and Natera (2013), for example, criticize the limited insights that exist regarding the drivers of change in a national IS, and the mechanisms that can explain its evolution and growth over time. In a very similar tone, Mack and Mayer (2016) highlight the little understanding regarding the interdepend- 
ence of the various components of an EE and its evolutionary dynamics. This is in addition to the critiques of the IS perspective reviewed above.

The most prominent difference between the two concepts is, arguably, the frameworks' focus. While the EE puts the entrepreneur at the center of its analysis, this element has been largely overlooked by the IS literature (Metcalfe \& Ramlogan, 2008). Instead, the IS tradition mainly focuses on the large, established firms and their role in generating innovations through R\&D (Freeman \& Soete, 1997; Autio \& Levie, 2014). Thus, the individual agency so prominent in the EE works has been generally missing in the IS literature (Autio, Kenney, Mustar, Siegel \& Wright, 2014). As a result, while the IS concept mainly envisions a top-down policy approach (Arocena \& Sutz, 2000), the EE is characterized by bottom-up dynamics, i.e. an emerging, self-organizing and self-sustaining system (Autio \& Levie, 2014).

The concern, however, is that when we have a multiplicity of similar concepts with little dialogue among them, we miss the connections, contradictions and overlaps that could help us build up better theory and policy practice regarding economic development. Much can be learned, we believe, if the two literatures feed into each other. Part I, entitled "The promise and the limits of bridging the entrepreneurial ecosystems and innovation systems approaches", therefore documents the similarities and differences between these two concepts, as well as their interlinkages and how the IS and the EE perspectives complement or contradict each other in their ability to explain specific dimensions of regional economic growth. In doing so, we build a first bridge - one that connects the two literature streams.

There are clearly multiple overlaps and areas for cross-fertilization. Chapter 2 , "Bridging the literature on innovation systems and entrepreneurial ecosystems: Cross-fertilizations for understanding knowledge-intensive, social and environmental entrepreneurship" by Renata Lèbre La Rovere, Marcelo Gerson Pessoa de Matos, Guilherme de Oliveira Santos and Antonio Pedro da Costa e Silva Lima, offers an overview of the EE and the IS concepts, focusing on the similarities and differences along three dimensions, the individual, the firm and the institutional context. The authors show that while the unit of analysis in the two approaches is different, both concepts are important for a more comprehensive understanding of innovative behavior by firms. The chapter describes how both theoretical and practice-oriented work on three specific types of entrepreneurship - knowledge-intensive, social and green - can not only benefit from but rather require the integration of the two literatures.

An understanding of the similarities and differences between the two approaches is an important first step for a more comprehensive view of economic development. The applicability of this knowledge on the EE and IS, however, may be limited to the "classical" (rooted in the realities of the most developed countries in North America and Europe) context. Whether the 
systems approaches can and should be "exported" to other regions where the need for growth may be even more pressing is a question that receives increasing - but still insufficient - attention (Tsvetkova, Pugh \& Schmutzler, 2019). Intuitively, the systems frameworks would need to be modified to be useful outside of the Global North.

Chapter 3, "Entrepreneurial ecosystems meet innovation systems: Building bridges from Latin America to the Global South" by Hugo Kantis, Manuel Gonzalo, Juan Federico and Sabrina Ibarra Garcia, provides an example of bridging the (eco)systems literature from the Latin American perspective. After summarizing the IS and the EE debate including the contribution by Latin American scholars, the authors explore how the two frameworks converge and diverge when applied in a less developed setting. They find that very specific business and social structures, limited access to finance, as well as weak demand conditions and institutions are important elements that need to be taken into consideration in order to understand Latin American (eco) systems. Another important element is the significant role that the government and policy (which are absent from the Schumpeterian view of innovation and entrepreneurship) tend to play in the efforts to promote innovation and entrepreneurship in Latin America. The (eco)systemic thinking in the region was strongly influenced by various local schools of thought and institutions, which provide a solid basis for adapting the EE and IS concepts for local applications. The other parts of the Global South seem to still lack such a thorough foundation for the reconceptualization of the (eco)systems approaches to the local conditions.

As highlighted by many chapters in this book, the EE and IS dynamics work at different levels. This difference is among the major limits to the integration and bridging of the frameworks. This point is well illustrated by the last chapter of the first part of the book, "The role of diaspora in entrepreneurial ecosystems and national innovation systems" by Veneta Andonova, Jonathan A. Perez-Lopez and Jana Schmutzler. In a particular case of the Balkan countries, a strong diaspora was instrumental in the development of a vibrant entrepreneurial community and the ecosystemic aspects surrounding and supporting it. However, the innovative performance of the region - especially that driven by larger, established firms - was not affected by the diaspora links. The careful explication of the processes that led to such divergent outcomes in the chapter highlights the potential of personal linkages among individuals to give rise to the systems-like entrepreneurial dynamics. For the systems-like innovative dynamics, at least in the classical sense of the national IS view, linkages among more institutionalized actors are more important. This observation also echoes the top-down versus bottom-up distinction between the EE and IS already stressed by the literature. 


\subsection{POLICY LESSONS FROM THE SYSTEMS PERSPECTIVES}

Both the EE and IS frameworks have heavily influenced public policy agendas. Before policy applications of the (eco)systemic logic become the mainstream, however, we need a better understanding of the lessons from the current research and practice. More critical reflections (and more empirical and theoretical explorations) are needed to ensure that countries and regions relying on the IS and EE approaches to improve their economic fortunes do indeed move in the desired direction. Our cautiousness stems from several important limitations of the current debates and practice. These limitations include underdeveloped tools to assess and to measure the EE and (to a lesser extent) the IS; a lack of knowledge on the transferability of the (eco)systems approaches to the underdeveloped settings with weak institutions, lagging preconditions and very different cultures; and the overemphasis of the current "classical" systems concepts on patented innovation and high-growth firms, which are not necessarily the best correlates with wellbeing and can, in fact, be destructive.

In the past, industrial policy interventions - often based at least in part on some (eco)systemic logic - have been heavily criticized, as is the case, for example, of Porter's clusters. A lacking consent regarding the definition of clusters has led Martin and Sunley (2003) to affirm that "we know what they're called, but defining precisely what they are is much more difficult" (p.10). A lacking theoretical underpinning, the lack of clear boundaries and no clear measurement approach to clusters were further critiques. It seems that history repeats itself with the newly emerging frameworks of EE and IS. For example, there is no commonly agreed upon definition of what an EE is (Stam, 2015). Instead, there is a collection of different definitions (e.g. Malecki, 2018). And while this might not be the case for IS, both concepts have been criticized for being undertheorized, offering plenty of description but little analysis (Lorentzen, 2009; Edquist, 2010).

The vagueness was perhaps a reason for the wide proliferation of the (eco)systemic approaches across the world. The practical applications rarely involved a critical assessment of applicability in general or concerning specific elements of the applied concepts. The fact that the published and widely cited research is quite narrow geographically (e.g. Spigel, 2018; Texeira, 2013) only exacerbates the gap in our understanding of how the systems logic works in various contexts. As noted by Spigel (2018), the commonly accepted lists of ecosystem attributes are mainly based on case studies in an increasing number of regions of the United States (US) and Western Europe and, as such, are embedded in the Anglo-American economic and social systems. 
This geographical myopia is dangerous; it implicitly assumes a well-functioning institutional context (Spigel, 2018), which for a developing or even a transition country is usually not the case (Tsvetkova, Schmutzler \& Suarez, 2017). Research has shown that context matters both for innovation (Freeman, 2002; Tsvetkova, Schmutzler, Suarez \& Faggian, 2017) and entrepreneurship (Welter, 2011). As such, it is not clear whether EE and IS in different contexts - peripheral regions in the Global North or regions in the Global South - have the same or similar attributes (Spigel \& Harrison, 2018). Similarly, the insufficient variety of the case studies focused on systemic aspects of regional economic performance limits the design of appropriate tools to measure or develop public policies to foster systemic dynamics (Godin, 2009).

In terms of the (eco)systems' outcomes, the current research appears to be excessively focused on high-growth entrepreneurship and patenting. The EE are usually defined as those that generate high-growth entrepreneurship and, in fact, some scientific contributions have linked the success of an EE to unicorns (Acs, Stam, Audretzch \& O'Connor, 2017). Yet, where successful entrepreneurship is apparent, there must be a strong EE. The literature's focus on successful case studies might be misleading for public policy-makers, as it limits our insights into what triggers the emergence and what drives the development of an EE or an IS in regions with lagging preconditions (Mack and Mayer, 2016; Albuquerque, 2007). Additionally, not only have the recent cases of unicorns, such as WeWork, failed to fulfill expectations, they call into question this exaggerated focus on high growth (see also Shearmur, 2019). Empirically, the evidence is not as convincing either. Grillitsch and Nilsson (2017), for example, showed that there is "no evidence [...] that knowledge-intensive firms grow faster in knowledge-rich regions" (p.1228).

Similarly, the implicit assumption exists that innovation - often equated with R\&D or patents - usually takes place in firms located in large, urban Northern agglomerations. Yet, the recent upsurge in frugal innovation (e.g. Bhatti, 2012; Weyrauch \& Herstatt, 2017) or reverse innovation (von Zedtwitz, Corsi, Søberg \& Frega, 2015) has shown that innovation - when understood in the Schumpeterian tradition as "creative destruction" - can be found in diverse settings, including the bottom-of-the-pyramid or the informal economy. These results uncover yet another bias inherent in innovation studies; with the overemphasis on patents or product innovation, different kinds of innovations such as the organizational or process varieties remain undetected or understudied (Metcalfe \& Ramlogan, 2008). In other words, "We often assume that these frontiers of science will benefit only the richer nations of the world [... But] in fact resource-poor settings can actually drive innovation, demanding ingenious product designs that are less expensive, and easier to use, and require less infrastructure. It is also easier to disrupt the technological status quo in the 
absence of entrenched commercial interests organised around existing products" (Elias, 2006, p. 540). Along these lines, Shearmur (2017) emphasizes the existing pro-urban bias regarding innovation and creativity. Generally, studies on innovation and its geography seem to assume that innovation activities occur - due to easier access to interactions and information exchange - primarily in cities. Yet, only because one does not observe something doesn't mean that it does not exist; it may as well be caused by the data biased towards cities (Shearmur, 2017). Governments and international organizations increasingly realize this drawback of the innovation perception. The OECD Centre for Entrepreneurship, SMEs, Regions and Cities is initiating a stream of work on rural innovation. In 2015, the US Department of Agriculture's Rural Establishment Innovation Survey was released.

Additionally, when considering the broad definition of an IS as opposed to a narrow one, the scope of an IS analysis goes beyond R\&D and science and technology, taking into consideration cultural, geographical and historical processes which account for differences in development trajectories and institutional evolution (Cassiolato \& Lastres, 2008; Lundvall, Joseph, Chaminade \& Vang, 2011). Yet, the frameworks' insights into the factors which may break down a certain lock-in in contexts with lagging preconditions is still limited, lacking a clear guidance for testable propositions and policy recommendations especially for the developing world (Lundvall, 2007b; Albuquerque, 2007; Lorentzen, 2009).

As a result, there is a clear need for diverse contributions that explore the relevance and applicability of the systemic concepts in a range of settings with the goal of learning policy lessons. The second part of the book includes several contributions with immediate policy implications.

Given the centrality of knowledge and learning to all systemic perspectives, Part II starts with a thorough analysis of the role that universities play in supporting social entrepreneurship, particularly in the less developed contexts. In their chapter "Beyond intellectual property and rich infrastructure: A community service learning perspective on universities' supportive role towards social entrepreneurs", Abel Diaz Gonzalez, Nikolay A. Dentchev and Maria del Carmen Roman Roig use the community service learning perspective within the context of social entrepreneurship to demonstrate that universities in less prosperous environments can support EE by leveraging the critical mass of their students, faculty and staff members. They can be highly successful in doing so even in the absence of a rich infrastructure or intellectual property. The chapter is the result of a qualitative research in Bolivia. It puts together an immediately useful list of 18 basic activities for students, faculty, staff members and the community that promote social entrepreneurs in this country.

Chapter 6, "The entrepreneurial propensity of the Swedish national innovation system: New challenges for policy-makers" by Jon Mikel 
Zabala-Iturriagagoitia, zooms in on a more common topic within the (eco) systems literature, knowledge-intensive entrepreneurship. Using the example of Sweden, a country where very high investments in science and technology did not translate into a comparable surge in innovative entrepreneurship (the so-called Swedish paradox), the author studies the entrepreneurial propensity of IS. He argues for a holistic approach to knowledge-intensive entrepreneurship and emphasizes the importance of both the supply and demand conditions for this type of entrepreneurship to thrive. Public procurement of innovation is named as an efficient tool to ensure that the demand is sufficiently strong to drive growth in knowledge-intensive entrepreneurship.

The chapter by José Eduardo Cassiolato, Maria Gabriela v. B. Podcameni, Helena Maria Martins Lastres and Maria Cecília Junqueira Lustosa, "Territory, development and systemic innovation: A Southern perspective", moves away from learning and innovation and focuses on the industrial dimension instead. The chapter presents the Local Innovation and Production System (LIPS) framework specifically developed to adapt the systemic approaches of the Global North to Latin American conditions. As such, this chapter complements the theoretical considerations developed in Chapter 3.

LIPS is highly influential in the region and was a successful tool for regional revitalization in some parts of Brazil (Podcameni, Cassiolato, Lustosa, Marcelino \& Rocha, 2019). The experience of developing the LIPS approach offers a prime example of how popular approaches that originated in the Global North can be modified for local applications elsewhere. Specifically, the LIPS adopts the broad notion of IS with an explicit focus on the territorial context, including society and nature, as crucial elements of innovation and local development and establishes a bridge between the micro, meso and macro levels and integrates social, economic and political dimensions as well as hierarchies and power elements. Such a comprehensive approach appears the most fitting for the realities of the less developed economies (Schmutzler, Suarez, Tsvetkova \& Faggian, 2017).

The last chapter of Part II, "The complementarity approach to understanding entrepreneurship and innovation ecosystems taxonomy" by Maksim Belitski and Andrew Godley proposes a synergy framework for understanding (eco) systemic concepts by focusing on EE. The authors show how four components - entrepreneurial actors, resource providers, entrepreneurial networks and connectivity and entrepreneurial culture - complement each other in driving economic development through entrepreneurship. The power of this approach is in its universal applicability - the local assessments of the existing preconditions for the development of EE, for example, can rely on these components in both developed and underdeveloped contexts. Most importantly, however, the authors demonstrate that the components work in a synergy and in some cases 
can substitute for each other, which is of particular relevance for the territories that lack in resources and may have underdeveloped one or more components.

\subsection{THE OVERLOOKED DIMENSIONS OF SYSTEMS PERSPECTIVES}

The unintended consequences of the overfascination with high-growth entrepreneurship and patent-based innovation within the EE and IS literature can be the omission of a range of important topics and considerations from both the public policy and practice attention and the academic discourse.

For example, equating the idea of high growth with productive entrepreneurs might be unjustified. William Baumol (1990) differentiated the productive, the unproductive and the destructive entrepreneur. Particularly, he stated that "unproductive entrepreneurship takes many forms. Rent seeking, often via activities such as litigation and takeovers, and tax evasion and avoidance efforts seem now to constitute the prime threat to productive entrepreneurship" (p.915). The potential bias that stems from equating the high-growth entrepreneurship or patent-based innovation with success limits our understanding of where innovation and entrepreneurship take place, as aptly illustrated by Shearmur (2019). In fact, the accumulating evidence suggests that there are many other (often overlooked) sources of success in regional wellbeing. For example, even in the US, one of the most developed and growth-oriented economies, the net effects of self-employment on job creation is considerably larger than the effects of paid employment (Tsvetkova, Partridge \& Betz, 2019). Likewise, also in the US, small and medium-sized cities are outperforming large urban areas in terms of population and employment growth (Partridge, 2010). This phenomenon of "large is not necessarily beautiful" applies perhaps even more outside of the Global North. In the developing countries, secondary cities and rural non-agricultural sectors offer better prospects for poverty reduction and inclusive growth (Christiaensen \& Todo, 2013; Christiaensen, Weerdt \& Todo, 2013). Despite this growing evidence, economic development policies and the academic debate are often driven by the considerations of the "traditional" measures of productivity and economic growth.

But the policy roles and goals, as well as the academic and policy practice discussion, can go beyond that (Fagerberg, 2017; Shearmur, 2019), as, for instance, in the case of the so-called mission-oriented policies with specific aims that target solutions for societal problems (Mowery, 2011). Additionally, against the backdrop of the Sustainable Development Goals, the need for a transition towards a more sustainable economic system is becoming more evident and urgent (Nill \& Kemp, 2009). The limitation and bias generated through an excessive emphasis on high growth or patents as a way to measure the success of EE and IS become evident. 
The omission of an array of important topics and dimensions from the (eco) systems-focused debates is prevalent both in the developed and the developing contexts. In the Global South, high-growth entrepreneurship and patenting are not meaningful indicators of economic performance. They are not meaningful goals either (Tsvetkova et al., 2019). More pressing challenges, such as informal entrepreneurship, inclusivity and broad-based and incremental innovations, are more relevant.

In the industrialized developed countries, in a similar vein, not enough attention is paid to inclusive entrepreneurship, the innovation-inclusiveness nexus and related topics. Research has acknowledged for some time already that both entrepreneurship and innovation are gendered (Minniti, 2009; Kirkup \& Keller, 1992; Agnete Alsos, Ljunggren \& Hytti, 2013; Thébaut, 2015). In fact, Morris, Neumeyer, Jang and Kuratko (2018) show that EE consist of different social clusters, which impose boundaries along various types of entrepreneurship potentially excluding minorities or women altogether or depriving them from necessary (institutional) support that the EE should be generating. While this point had been made earlier (Thébaut, 2015), and despite the attention paid to the issues of the missing entrepreneurs by international organizations (for example, OECD \& EU, 2019), the efforts to remove barriers to entrepreneurship for underrepresented groups are still insufficient.

The omitted topics within the (eco)systems research are not limited to the focus of the inquiry. The complexities of the involved phenomena clearly call for a wider methodological variety. Not only quantitative but also qualitative approaches, particularly grounded in disciplines different from evolutionary economics or economic geography, can generate indispensable insights for the enhanced understanding of the ways EE and IS function and can be steered to generate greater welfare for all people.

Part III presents a few examples of work that expands the boundaries of the (eco)systemic literature by considering the main processes, such as entrepreneurship, from the unorthodox perspectives and by looking at the underexplored topics - at least in the "mainstream" research. Chapter 9, "Beyond entrepreneurial culture in the entrepreneurial ecosystems framework: Contributions from economic anthropology" by Maria Giulia Pezzi and Félix Modrego, is an example of the former. Drawing the attention of the reader to the fact that an EE cannot exist without entrepreneurial culture, the authors unpack this often overlooked dimension of an EE. Particularly in the case of high-growth entrepreneurship, which is often considered - for better or for worse - the cornerstone of EE at least in the developed countries, the societally accepted and encouraged cultural norms, such as risk taking, experimentation and innovation, are central to EE success. The chapter makes a case for an extended, anthropology-sensitive systemic approach to EE, which incorporates the view of entrepreneurship as a dynamic agency-based process of social 
change and is based on the view of culture as an enduring set of shared values and beliefs that molds a worldview welcoming entrepreneurial behavior.

The remainder of Part III sheds light on some of the overlooked topics. "Typifying latecomer social enterprises by ownership structure: Learning and building knowledge from innovation systems" by Jahan Ara Peerally and Claudia De Fuentes examines the performance of social enterprises in the emerging, less developed and developing - so-called latecomer - economies. In particular, the authors explore how the ownership structure of the latecomer social entrepreneurs and their links to actors within and outside their IS determine their knowledge stock, technological capabilities and impacts on development. This chapter is a great example of cross-fertilization across research fields that feeds into a better comprehension of certain elements of the (eco)systemic dynamics, in this case, using a toolkit from the management disciplines.

Based on empirical observations of urban labor markets in Africa, the term informal economy was born (Portes \& Haller, 2010). It is now widely accepted that the informal sector is not only a persistent phenomenon but also a growing one in many parts of the world. However, despite the recognition that informal innovations and informal entrepreneurship are a part of economic reality in many developing countries (Arocena \& Sutz, 2000), little attention has been paid to these aspects in both the IS and EE literature. Chapter 11, "Entrepreneurial ecosystems as a mechanism to promote economic formality in emerging economies: The case of Bogota" by Andres Guerrero Alvarado and Vinciane Servantie contributes to filling this gap. The authors focus on the EE in Bogota, Colombia's capital. Using network analysis, the chapter offers practical insights into the ways EE can contribute to transforming informal entrepreneurship into a formal one, which is among the biggest challenges for Latin America. Specifically, the authors argue that an explicit focus of support institutions and actors during the later stages of the entrepreneurial process on opportunity-based entrepreneurship poses a great barrier to the process of transformation.

\subsection{CONCLUDING REMARKS}

The aim of this book is two-fold. On the one hand, we want to show how a conversation between the two intimately linked, yet (so far mostly) independently studied, frameworks of EE and IS can advance the field of economic development studies. The chapters in the first part of the book demonstrate that not only is such a conversation fruitful, but in many ways necessary. Both frameworks are rooted in systemic thinking and learn from the insights and critiques that often stem from and are targeted at the systemic character of the concepts. At the same time, the clear differences between the two frameworks 
(demonstrated by various chapters in this book) can complement and feed into each other. For example, the individual agency of entrepreneurs, which is at the core of the EE approach, may under certain circumstances substitute for the institutional void that hinders development of an IS.

On the other hand, we aim to diversify research that analyses and applies these two frameworks both in terms of geography and topics. We believe that the book offers abundant material for researchers to understand that stepping outside of the already well-studied prosperous contexts of the Global North enables a better understanding of what is able (or not) to trigger the emergence of a supportive environment for entrepreneurship and innovation. The book also calls upon practitioners and policy-makers working to build such environments to go beyond the often applied copy-and-paste approach and instead use the regional culture and institutional context as a starting point. Similarly, such a diversification allows for the inclusion of overlooked dimensions, such as the Sustainable Development Goals or the informal economy. We hope that this book offers new insights that will give way to new research and discussions that promote a better-informed dialogue on innovation and entrepreneurship.

\section{NOTE}

1. Start-ups valued at more than 1 billion US dollars.

\section{REFERENCES}

Acs, Z. J., Autio, E., \& Szerb, L. (2014). National systems of entrepreneurship: Measurement issues and policy implications. Research Policy, 43(3), 476-94.

Acs, Z. J., Stam, E., Audretsch, D. B., \& O'Connor, A. (2017). The lineages of the entrepreneurial ecosystem approach. Small Business Economics, 49(1), 1-10.

Agnete Alsos, G., Ljunggren, E., \& Hytti, U. (2013). Gender and innovation: State of the art and a research agenda. International Journal of Gender and Entrepreneurship, 5(3), 236-56.

Albuquerque, E. D. M. E. (2007). Inadequacy of technology and innovation systems at the periphery. Cambridge Journal of Economics, 31(5), 669-90.

Arocena, R., \& Sutz, J. (2000). Looking at national systems of innovation from the South. Industry and Innovation, 7(1), 55-75.

Asheim, B. T. (2012). The changing role of learning regions in the globalising knowledge economy: A theoretical re-examination. Regional Studies, 46(8), 993-1004.

Asheim, B. T., Smith, H. L., \& Oughton, C. (2011). Regional innovation systems: Theory, empirics and policy. Regional Studies, 45(7), 875-91.

Autio, E., Kenney, M., Mustar, P., Siegel, D., \& Wright, M. (2014). Entrepreneurial innovation: The importance of context. Research Policy, 43(7), 1097-108.

Autio, E. \& Levie, J. (2014). Hard facts or soft insights? Fact-based and participative approaches to entrepreneurship ecosystems policy and management. In: Entrepreneurial Ecosystems, Innovation and Regional Competitiveness, Henley Business School, University of Reading. https://strathprints.strath.ac.uk/58813/1/ 
Autio_Levie_2014_Hard_facts_or_soft_insights_fact_based_and_participative approaches.pdf

Baumol, W. J. (1990). Entrepreneurship: Productive, unproductive, and destructive. Journal of Political Economy, 98(5), 893-921.

Bhatti, Y. A. (2012). What is frugal, what is innovation? Towards a theory of frugal innovation. SSRN. http://dx.doi.org/10.2139/ssrn.2005910

Breschi, S., \& Malerba, F. (1997). Sectoral innovation systems: Technological regimes, Schumpeterian dynamics, and spatial boundaries. In: C. Edquist (Ed.), Systems of Innovation: Technologies, institutions and organisations (pp. 130-56). London: Pinter.

Camagni, R. (1991). Local "milieu", uncertainty and innovation networks: Towards a new dynamic theory of economic space. In: Innovation Networks: Spatial Perspectives (pp. 121-44). London: Belhaven.

Carlsson, B., \& Stankiewitz, R. (1991). On the nature, function and composition of technological systems. Journal of Evolutionary Economics, 1, 93-118.

Cassiolato, J. E., \& Lastres, H. M. (2008). Discussing innovation and development: Converging points between the Latin American school and the innovation systems perspective? Georgia Institute of Technology.

Castellacci, F., \& Natera, J. M. (2013). The dynamics of national innovation systems: A panel cointegration analysis of the coevolution between innovative capability and absorptive capacity. Research Policy, 42(3), 579-94.

Christiaensen, L., De Weerdt, J., \& Todo, Y. (2013). Urbanization and Poverty Reduction: The role of rural diversification and secondary towns. Washington, DC: World Bank.

Christiaensen, L., \& Todo, Y. (2013). Poverty Reduction during the Rural-Urban Transformation: The role of the missing middle. Washington, DC: World Bank.

Colombelli, A., Paolucci, E., \& Ughetto, E. (2017). Hierarchical and relational governance and the life cycle of entrepreneurial ecosystems. Small Business Economics,1-17. https://doi.org/10.1007/s11187-017-9957-4

Cooke, P. (1998). Introduction: Origins of the concept. SSRN. https://ssrn.com/abstract $=1497770$

Doloreux, D. (2002). What we should know about regional systems of innovation. Technology in Society, 24, 243-63.

Doloreux, D., \& Parto, S. (2005). Regional innovation systems: Current discourse and unresolved issues. Technology in Society, 27, 133-53.

Edquist, C. (2005). Systems of innovation: Perspectives and challenges. In: J. Fagerberg, D. Mowery \& R. Nelson (Eds), Oxford Handbook of Innovation (pp. 181-208). Oxford: Oxford University Press.

Edquist, C. (2010). Systems of innovation perspectives and challenges. African Journal of Science, Technology, Innovation and Development, 2(3), 14-45.

Elias, C. J. (2006). Can we ensure health is within reach for everyone? Lancet, 368, S40-S41.

Fagerberg, J. (2017). Innovation policy: Rationales, lessons and challenges. Journal of Economic Surveys, 31(2), 497-512.

Feld, B. (2012). Startup Communities: Building an entrepreneurial ecosystem in your city. Chichester: John Wiley \& Sons.

Fischer, M. (2001). Innovation, knowledge creation and systems of innovation. Annals of Regional Science, 35, 199-216.

Freeman, C. (2002). Continental, national, and sub national innovation systems: Complementarity and economic growth. Research Policy, 31, 191-211. 
Freeman, C., \& Soete, L. (1997). The Economics of Industrial Innovation. Cambridge, MA: MIT Press.

Godin, B. (2009). National innovation system: The system approach in historical perspective. Science, Technology, and Human Values, 34(4), 476-501.

Grillitsch, M., \& Nilsson, M. (2017). Firm performance in the periphery: On the relation between firm-internal knowledge and local knowledge spillovers. Regional Studies, 51(8), 1219-31.

Isenberg, D. J. (2010). How to start an entrepreneurial revolution. Harvard Business Review, 88(6), 40-50.

Kirkup, G., \& Keller, L. S. (1992). Inventing Women: Science, technology, and gender. Cambridge: Polity Press.

Kreuzer, A., Mengede, K., Oppermann, A., \& Regh, M. (2018). Guide for Mapping the Entrepreneurial Ecosystem. Bonn: Deutsche Gesellschaft für Internationale Zusammenarbeit.

Lorentzen, J. (2009). Learning by firms: The black box of South Africa's innovation system. Science and Public Policy, 36(1), 33-45.

Lundvall, B.-A. (1988). Innovation as an interactive process: From user-producer interaction to the national innovation systems. In: G. Dosi, C. Freeman, R. Nelson, G. Silverberg \& L. Soete (Eds), Technology and Economic Theory. London: Pinter.

Lundvall, B.-Å. (1992). National Innovation Systems: Towards a theory of innovation and interactive learning. London: Pinter.

Lundvall, B.-A. (2002). Innovation, Growth and Social Cohesion: The Danish model. Cheltenham, UK and Northampton, MA, USA: Edward Elgar Publishing.

Lundvall, B.-Å. (2003). National innovation systems: History and theory. In: H. Hanusch \& A. Pyka (Eds), Elgar Companion to Neo-Schumpeterian Economics (pp. 872-81). Cheltenham, UK and Northampton, MA, USA: Edward Elgar Publishing.

Lundvall, B.-Å. (2007a). Innovation System Research: Where it came from and where it might go. Globelics Working Paper 2007-01.

Lundvall, B. Å. (2007b). National innovation systems: Analytical concept and development tool. Industry and Innovation, 14(1), 95-119.

Lundvall, B.-Å., Johnson, B., Andersen, E. S., \& Dalum, B. (2002). National systems of production, innovation and competence building. Research Policy, 31, 213-31.

Lundvall, B. Å., Joseph, K. J., Chaminade, C., \& Vang, J. (Eds) (2011). Handbook of Innovation Systems and Developing Countries: Building domestic capabilities in a global setting. Cheltenham, UK and Northampton, MA, USA: Edward Elgar Publishing.

Mack, E., \& Mayer, H. (2016). The evolutionary dynamics of entrepreneurial ecosystems. Urban Studies, 53(10), 2118-33.

Malecki, E. J. (2018). Entrepreneurship and entrepreneurial ecosystems. Geography Compass, 12(3), e12359.

Malmberg, A., \& Maskell, P. (1997). Towards an explanation of regional specialization and industry agglomeration. European Planning Studies, 5(1), 25-41.

Marshall, A. (1920 [1890]). Principles of Economics. London: Macmillan \& Co.

Martin, R., \& Sunley, P. (2003). Deconstructing clusters: Chaotic concept or policy panacea? Journal of Economic Geography, 3(1), 5-35.

Mason, C., \& Brown, R. (2014). Entrepreneurial ecosystems and growth oriented entrepreneurship. Background paper prepared for the workshop organised by the OECD LEED Programme and the Dutch Ministry of Economic Affairs on Entrepreneurial Ecosystems and Growth Oriented Entrepreneurship, The Hague. 
McCann, P., \& Ortega-Argilés, R. (2013). Modern regional innovation policy. Cambridge Journal of Regions, Economy and Society, 6(1),1-30.

Metcalfe, S., \& Ramlogan, R. (2008). Innovation systems and the competitive process in developing economies. Quarterly Review of Economics and Finance, 48(2), 433-46.

Minniti, M. (2009). Gender issues in entrepreneurship. Foundations and Trends in Entrepreneurship, 5(7-8), 497-621.

Moore, T. (1963). Ecosystems. American Biology Teacher, 25(4), 249-52. doi:10 $.2307 / 4440335$

Morris, M. H., Neumeyer, X., Jang, Y., \& Kuratko, D. F. (2018). Distinguishing types of entrepreneurial ventures: An identity-based perspective. Journal of Small Business Management, 56(3), 453-74.

Mowery, D. C. (2011). Federal policy and the development of semiconductors, computer hardware and computer software: A policy model for climate change R\&D? In: R. M. Henderson and R. G. Newell (Eds), Accelerating Energy Innovation: Insights from multiple sectors (pp. 159-88). Chicago, IL: University of Chicago Press.

Nelson, R. (Ed.) (1993). National Innovation Systems: A comparative analysis. Oxford: Oxford University Press.

Nelson, R., \& Rosenberg, N. (1993). Technical innovation and national systems. In: National Innovation Systems: A comparative analysis. Oxford: Oxford University Press.

Nill, J., \& Kemp, R. (2009). Evolutionary approaches for sustainable innovation policies: From niche to paradigm? Research Policy, 38(4), 668-80.

OECD (2014). Job Creation and Local Economic Development. Paris: OECD Publishing. https://doi.org/10.1787/9789264215009-en

OECD (2019). Local Entrepreneurship Ecosystems and Emerging Industries: Case study of Malopolskie, Poland. OECD Local Economic and Employment Development (LEED) Working Papers, No. 2019/03. Paris: OECD Publishing. https://doi.org/10.1787/d99ba985-en

OECD \& European Union (2019). The Missing Entrepreneurs 2019: Policies for inclusive entrepreneurship. Paris: OECD Publishing. https://doi.org/10.1787/3ed84801 -en

Partridge, M. D. (2010). The duelling models: NEG vs amenity migration in explaining US engines of growth. Papers in Regional Science, 89(3), 513-36.

Podcameni, M. G., Cassiolato, J. E., Lustosa, M. C., Marcelino, I., \& Rocha, P. (2019). Exploring the convergence between sustainability and local innovation systems from a Southern perspective: What Brazilian empirical evidence has to offer. Local Economy, 34(8), 825-37.

Porter, M. E. (2000). Location, competition, and economic development: Local clusters in a global economy. Economic Development Quarterly, 14(1), 15-34.

Portes, A., \& Haller, W. (2010). The informal economy. In: N. Smelser \& R. Swedberg (Eds), The Handbook of Economic Sociology. Princeton, NJ: Princeton University Press.

Pugh, R. (2014). Regional Innovation Policy and Economic Development: The case of Wales. Doctoral dissertation, Cardiff University.

Schmutzler, J., Suarez, M., Tsvetkova, A., \& Faggian, A. (2017). Introduction: A context-specific two-way approach to the study of innovation systems in developing and transition countries. In: A. Tsvetkova, J. Schmutzler, M. Suarez \& A. Faggian (Eds), Innovation in Developing and Transition Countries. Cheltenham, UK and Northampton, MA, USA: Edward Elgar Publishing. 
Schumpeter, J. (2003 [1911]). Theorie der wirtschaftlichen Entwicklung. In: Joseph Alois Schumpeter (pp. 5-59). Boston, MA: Springer.

Scotland Can Do (2018). Scottish Entrepreneurial Ecosystem Guide. http://cando.scot/ wp-content/uploads/2019/02/V3-Scottish-Entrepreneurial-Ecosystem-Guide-Feb -2019.pdf

Shearmur, R. (2017). Urban bias in innovation studies. In: H. Bathelt, P. Cohendet, $\mathrm{S}$. Henn \& L. Simon (Eds), The Elgar Companion to Innovation and Knowledge Creation (pp. 440-56). Cheltenham, UK and Northampton, MA, USA: Edward Elgar Publishing.

Shearmur, R. (2019). Why we should stop conflating cities with innovation and creativity. www.citylab.com/perspective/2019/12/smart-city-innovation-clusters-rural -creativity-research/602626/

Spigel, B. (2017). The relational organization of entrepreneurial ecosystems. Entrepreneurship Theory and Practice, 41(1), 49-72.

Spigel, B. (2018). Envisioning a new research agenda for entrepreneurial ecosystems: Top-down and bottom-up approaches. In: J. A. Katz \& A. Corbett, A. (Eds), Reflections and Extensions on Key Papers of the First Twenty-Five Years of Advances (pp. 127-47). Emerald Publishing.

Spigel, B., \& Harrison, R. (2018). Toward a process theory of entrepreneurial ecosystems. Strategic Entrepreneurship Journal, 12(1), 151-68.

Stam, E. (2015). Entrepreneurial ecosystems and regional policy: A sympathetic critique. European Planning Studies, 23(9), 1759-69.

Stam, E., \& Spigel, B. (2017). Entrepreneurial ecosystems. In: R. Blackburn, D. de Clercq \& J. Heinonen (Eds), The SAGE Handbook of Small Business and Entrepreneurship. London: SAGE.

Teixeira, A. A. (2014). Evolution, roots and influence of the literature on national systems of innovation: A bibliometric account. Cambridge Journal of Economics, $38(1), 181-214$.

Thébaud, S. (2015). Status beliefs and the spirit of capitalism: Accounting for gender biases in entrepreneurship and innovation. Social Forces, 94(1), 61-86.

Tsvetkova, A., Partridge, M., \& Betz, M. (2019). Self-employment effects on regional growth: A bigger bang for a buck? Small Business Economics, 52(1), 27-45.

Tsvetkova, A., Pugh, R., \& Schmutzler, J. (2019). Beyond global hubs: Broadening application of systems approaches. Local Economy, 34(8), 755-66.

Tsvetkova, A., Schmutzler, J., \& Suarez, M. (2017). Epilogue: Innovation systems in developing and transition countries: What is different, what is missing and what are the implications? In: A. Tsvetkova, J. Schmutzler, M. Suarez \& A. Faggian (Eds), Innovation in Developing and Transition Countries (pp. 236-44). Cheltenham, UK and Northampton, MA, USA: Edward Elgar Publishing.

Tsvetkova, A., Schmutzler, J., Suarez, M., \& Faggian, A. (Eds) (2017). Innovation in Developing and Transition Countries. Cheltenham, UK and Northampton, MA, USA: Edward Elgar Publishing.

Uriona-Maldonado, M., dos Santos, R. N., \& Varvakis, G. (2012). State of the art on the systems of innovation research: A bibliometrics study up to 2009. Scientometrics, 91(3), 977-96.

von Zedtwitz, M., Corsi, S., Søberg, P. V., \& Frega, R. (2015). A typology of reverse innovation. Journal of Product Innovation Management, 32(1), 12-28.

Welter, F. (2011). Contextualizing entrepreneurship: Conceptual challenges and ways forward. Entrepreneurship Theory and Practice, 35(1), 165-84. 
Weyrauch, T., \& Herstatt, C. (2017). What is frugal innovation? Three defining criteria. Journal of Frugal Innovation, 2(1), 1.

World Bank (2010). Innovation Policy: A guide for developing countries. Washington, DC: World Bank.

World Bank (2018). Tech Startup Ecosystem in West Bank and Gaza: Findings and recommendations. Washington, DC: World Bank. 